\title{
Gum ghatti based novel electrically conductive biomaterials: A study of conductivity and surface morphology
}

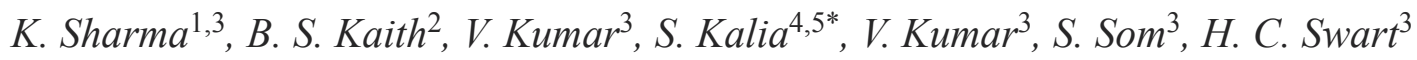 \\ ${ }^{1}$ Department of Chemistry, Shoolini University of Biotechnology and Management Sciences, Solan, 173212 Himachal \\ Pradesh, India \\ ${ }^{2}$ Department of Chemistry, Dr. B.R. Ambedkar National Institute of Technology, Jalandhar, 144011 Punjab, India \\ ${ }^{3}$ Department of Physics, University of the Free State, P.O. Box 339, ZA9300 Bloemfontein, South Africa \\ ${ }^{4}$ Department of Civil, Chemical, Environmental and Materials Engineering, University of Bologna, Via Terracini 28, \\ 40131 Bologna, Italy \\ ${ }^{5}$ Department of Chemistry, Bahra University, Shimla Hills, 173234 Waknaghat, Dist. Solan (H.P.) India
}

Received 6 October 2013; accepted in revised form 4 December 2013

\begin{abstract}
Gum ghatti-cl-poly(acrylamide-aniline) interpenetrating network (IPN) was synthesized by a two-step aqueous polymerization method, in which aniline monomer was absorbed into the network of gum ghatti-cl-poly(acrylamide) and followed by a polymerization reaction between aniline monomers. Initially, semi-IPN based on acrylamide and gum ghatti was prepared by free-radical copolymerization in aqueous media with optimized process parameters, using $N, N^{\prime}$-methylenebis-acrylamide, as cross-linker and ammonium persulfate, as an initiator system. Optimum reaction conditions affording maximum percentage swelling were: solvent $[\mathrm{mL}]=12$, Acrylamide $(\mathrm{AAm})\left[\mathrm{mol} \cdot \mathrm{L}^{-1}\right]=1.971$, Ammonium peroxydisulfate (APS) $\left[\mathrm{mol} \cdot \mathrm{L}^{-1}\right]=0.131 \cdot 10^{-1}, N, N^{\prime}$-methylene-bis-acrylamide $(\mathrm{MBA})\left[\mathrm{mol} \cdot \mathrm{L}^{-1}\right]=0.162 \cdot 10^{-1}$, reaction time $[\mathrm{min}]=210$, temperature $\left[{ }^{\circ} \mathrm{C}\right]=100$ and $\mathrm{pH}=7.0$. The resulting IPN was doped with different protonic acids. The effect of the doping has been investigated on the conductivity and surface morphology of the IPN hydrogel. The maximum conductivity was observed with $1.5 \mathrm{~N} \mathrm{HClO}_{4}$ concentration. The morphological, structural and electrical properties of the candidate polymers were studied using scanning electron micrscopy (SEM), Fourier transform infrared spectroscopy FTIR and two-probe method, respectively.
\end{abstract}

Keywords: polymer gels, gum ghatti, interpenetrating network, electrical properties

\section{Introduction}

Recently, the modifications of crosslinked hydrogels with conducting polymers (CPs) lead to the preparation of multifunctional electrical conducting materials. This offers a facile methodology to combine the superior properties of CPs with the highly crosslinked hydrogels. The resultant hydrogel exhibit quite different characteristics from the individual materials, for example, the electrical conductivity and thermal stability of the resultant hydrogels have much improved over that of bare hydrogel $[1,2]$.
They also showed good process ability, chemical stability towards dopants and solubility under readily accessible conditions [3]. Conducting hydrogels have been used in fuel cells, super capacitors; dye sensitized solar cells and rechargeable lithium batteries [4]. Many efforts have been made to successfully modify the crosslinked hydrogels with the different materials as polyaniline, graphite, $\mathrm{Cu}$, etc. by a two-step synthesis method [5-8].

On the other hand, superabsorbent hydrogels (SAHs) are three-dimensional (3D) polymer networks that

\footnotetext{
${ }^{*}$ Corresponding author, e-mail: susheel.kalia@gmail.com (C) BME-PT
} 
can absorb water and swell to several times their initial dry volume. The crosslinked hydrogels have outstanding properties such as, hydrophilicity, excellent swelling capacity, lack of toxicity, and biocompatibility which makes them potential candidates to use in a variety of fields [9]. They can respond to slight changes in temperature, $\mathrm{pH}$ and light are area of extensive research because of their responsive properties [10]. Hydrogels are particularly useful in agriculture and horticulture, sensors, biomedical and pharmaceutical applications $[9,11,12]$.

Gums are important families of natural polymers derived from the seeds or tubers of plants and gum ghatti is a promising polysaccharide [13]. The polysaccharide gums have a different molecular structure and properties, but their common advantages such as renewable, biodegradable, nontoxic, biocompatibility, etc. make them useful in extensive applications as a commercial polymer in many areas $[14,15]$.

Among the conducting polymers (CPs), polyaniline (PANI) is a well-known versatile conducting material, which has found particular biological utility due to its easy synthesis, low cost, tunable conductivity, and environmental stability $[16,17]$. The conductivity of PANI can be controlled by the protonation of the imine sites on the main polymer chain. It is well reported in literature that the electrical conductivity of PANI depends mainly on the dopant concentration, oxidant-to-monomer ratio, the rate of addition of oxidants, the nature of dopants, purity of monomer and polymerization time, etc. [18-20]. Crosslinked hydrogels based on gum ghatti were studied to determine their absorbency and biodegradability [21, 22]. Various authors synthesized electrical conducting hydrogels based on different polysaccharides and polyaniline through graft copolymerization [23-26]. The produced materials have found applications in the area of biosensors and gas sensors $[3,25]$. The present work reports on the synthe- sis of electrical conducting IPN biopolymer based on Gg-cl-poly(AAm) and PANI in hot air oven. Initially, a semi-IPN based on AAm and gum ghatti has been synthesized using free radical copolymerization with optimized process parameters (viz. concentration of monomer, solvent and crosslinker, reaction time, $\mathrm{pH}$ of solution, etc.). The synthesis of IPN hydrogel consisting of poly(acrylamide-aniline)grafted gum is also reported. The effects of protonic acid dopants on the conductivity and surface morphology of the IPN hydrogel were investigated. This study has been extended to the examination of the synthesized crosslinked hydrogels for their thermal stability. The main advantage of present work is to explore the use of natural resources and increase their usefulness in broader prospective by chemical modifications.

\section{Experimental section \\ 2.1. Materials}

Gum ghatti $\left(G_{\mathrm{g}}\right)$ was purchased from Sigma Aldrich. Ammonium peroxydisulfate (APS) (99.5\%), $N, N^{\prime}-$ methylene-bis-acrylamide (MBA), aniline (99.5\%) and all the protonic acids ( $>99 \%$ purity) were purchased from Merck India Co. Deionized water was used for all reactions.

\subsection{Preparation of Gg-cl-poly(AAm)}

A polymer matrix composed of Gg-cl-poly(AAm) was prepared by using MBA as crosslinker and APS as initiator in hot air oven. In a typical experiment, $0.5 \mathrm{~g}$ gum ghatti was dissolved in $10 \mathrm{~mL}$ of triple distilled water in a reaction flask. To this reaction mixture, a calculated amount of APS and MBA were added followed by the addition of AAm under continuous stirring. The reaction container was kept in a hot air oven at $60^{\circ} \mathrm{C}$ for a fixed time period and the resulting product was freed from homopolymer through solvent extraction using acetone. Finally, the product was dried in a hot air oven at $50^{\circ} \mathrm{C}$. Var-

Table 1. Effect of different reaction parameters on Gg-cl-poly(AAm) and Gg-cl-poly(AAm-ipn-aniline)

\begin{tabular}{|c|c|c|c|c|c|c|c|c|c|c|c|}
\hline \multirow[b]{2}{*}{ Sample code } & \multicolumn{8}{|c|}{ Optimized reaction parameters } & \multirow{2}{*}{$\begin{array}{c}\text { Mean } \\
\text { percentage } \\
\text { swelling } \\
\text { (M) }\end{array}$} & \multirow[b]{2}{*}{ \pm SD } & \multirow[b]{2}{*}{$\pm \mathrm{SE}$} \\
\hline & $\begin{array}{c}\text { Back- } \\
\text { bone } \\
{[\mathrm{g}]}\end{array}$ & $\begin{array}{c}\text { Initiator } \\
{[\mathrm{mol} / \mathrm{L}]} \\
\cdot 10^{-1} \\
\end{array}$ & $\begin{array}{l}\text { Time } \\
\text { [min] }\end{array}$ & $\begin{array}{c}\text { Amt. of } \\
\text { solvent } \\
{[\mathrm{mL}]}\end{array}$ & pH & $\begin{array}{c}\text { Monomer } \\
{[\mathrm{mol} / \mathrm{L}]}\end{array}$ & $\begin{array}{c}\text { Cross-linker } \\
{[\mathrm{mol} / \mathrm{L}]} \\
\cdot 10^{-1} \\
\end{array}$ & $\begin{array}{c}\text { Temperature } \\
{\left[{ }^{\circ} \mathrm{C}\right]}\end{array}$ & & & \\
\hline $\begin{array}{l}\text { Gg-cl- } \\
\text { poly(AAm) }\end{array}$ & 0.5 & 0.131 & 210 & 12 & 7 & 1.971 & 0.162 & 60 & 850.43 & 24.36 & 14.01 \\
\hline $\begin{array}{l}\text { Gg-cl- } \\
\text { poly(AAm-ipn- } \\
\text { aniline) }\end{array}$ & 0.5 & 0.131 & 210 & 12 & 7 & $2.219 \cdot 10^{-4}$ & 0.162 & 60 & 686.30 & 12.50 & 7.20 \\
\hline
\end{tabular}

Where, number of replication $=3, \mathrm{M}-$ mean, $\pm \mathrm{SD}-$ standard deviation and $\pm \mathrm{SE}-$ standard error of mean. 
ious reaction parameters such as monomer concentration, initiator concentration, cross linker concentration, polymerization time, temperature, solvent and $\mathrm{pH}$ of the reaction mixture were optimized to get the maximum percentage swelling $\left(P_{\mathrm{s}}\right)$ (Table 1).

\subsection{Preparation of}

\section{Gg-cl-poly(AAm-ipn-aniline)}

On the basis of the Gg-cl-poly(AAm) superabsorbent, a Gg-cl-poly(AAm-ipn-aniline) hydrogel was prepared according to the following procedure. For each experiment Gg-cl-poly(AAm) (0.5 g) was added to an aqueous medium with $2.129 \mathrm{~mol} \cdot \mathrm{L}^{-1}$ of aniline monomer. The resulting solution was kept for $16 \mathrm{~h}$ at room temperature, which resulted in the absorption of aniline monomer in the Gg-cl-poly (AAm) network and the formation of a swollen sample. To this mixture a preoptimized initiator $\left(0.131 \cdot 10^{-1} \mathrm{~mol} \cdot \mathrm{L}^{-1}\right)$ and crosslinker concentration $\left(0.162 \cdot 10^{-1} \mathrm{~mol} \cdot \mathrm{L}^{-1}\right)$ was added during constant stirring. When a small amount of APS solution was added slowly into the solution at the polymerization step, the slightly brown color of the reaction solution changed to slightly green. The resulting solution was kept in hot air oven at $60^{\circ} \mathrm{C}$ for a preoptimized time period $(210 \mathrm{~min})$. The resulting product was washed with 1-methyl-2-pyrrolidone (NMP) to remove the homopolymers. Finally, the product was dried in a vacuum oven at $50^{\circ} \mathrm{C}$ and a solid Gg-clpoly(AAm-aniline) IPN structure was obtained. Optimization was done with respect to aniline concentration (Table 1). The synthesis of the conducting IPN was carried out in a similar fashion containing $0.5 \mathrm{~N}$ aqueous acidic media of protonic acids such as $\mathrm{H}_{2} \mathrm{SO}_{4}, \mathrm{HCl}, \mathrm{HClO}_{4}$, PTS or $\mathrm{HNO}_{3}$ in the reaction flask, respectively. The conducting IPN was also synthesized at various concentrations of $\mathrm{HClO}_{4}$ varying from $0.5-2.5 \mathrm{~N}$, respectively.

\subsection{Characterizations}

$\mathrm{X}$-ray diffraction (XRD) patterns were recorded on a Phillips X-ray diffractometer with $\mathrm{Cu}-\mathrm{K}_{\alpha}$ radiation (1.54 $\AA$ ) for a wide range of Bragg's angles $2 \theta$ $(10<\theta<60)$ at the scanning rate of $1^{\circ}$ per minute. The operating voltage and current for the X-ray gun were $40 \mathrm{kV}$ and $40 \mathrm{~mA}$, respectively. Fourier transformed infrared (FTIR) spectral studies of raw and cross linked samples were recorded using a Perkin Elmer FTIR spectrophotometer using KBr pellets. The analysis conditions were: wavenumber range of $600-4000 \mathrm{~cm}^{-1}, 4 \mathrm{~cm}^{-1}$ resolution, 40 scans, and room temperature $\left(25^{\circ} \mathrm{C}\right)$. Thermal gravimetric analysis (TGA) spectra were taken by using a Perkin Elmer Diamond instrument in air at a heating rate of $10^{\circ} \mathrm{C} / \mathrm{min}$. A Shimadzu SSX-550 Superscan scanning electron microscope (SEM) was used to capture the SEM images at different magnification. Room-temperature d.c. electrical conductivity was measured by the two-probe technique using a Keithley 2400 source meter. The electrical conductivity measurements were made on compressed circular pellets (mass $\sim 0.2 \mathrm{~g}$, diameter $=8 \mathrm{~mm}$, thickness $=1 \pm 0.07 \mathrm{~mm}$, pressure $=8 \mathrm{t} / \mathrm{cm}^{2}$ ). The resistivity of the sample was calculated using the Equation (1) [26]:

$\rho=R \frac{A}{I}$

where $\rho, R, A$, and $l$ are resistivity $[\Omega \cdot \mathrm{cm}]$, resistance $[\Omega]$, area of the pellet $\left[\mathrm{cm}^{2}\right]$, length of the pellet $[\mathrm{cm}]$, respectively.

Conductivity can be computed using the relationship, $\sigma=1 / \rho$, where $\sigma$ is the conductivity, and $\rho$ the resistivity of the sample.

\subsection{Swelling behavior}

The pre-weighted crosslinked hydrogel was immersed in excessive distilled water and kept undisturbed for $16 \mathrm{~h}$ at room temperature. The swollen hydrogel was dried with filter paper and drained for some time until no free water remained. After weighing the swollen hydrogel on an analytical balance (accuracy $\pm 0.00001 \mathrm{~g})$, the percentage swelling $\left(P_{\mathrm{s}}\right)$ may be calculated by using the Equation (2) [27]:

$P_{\mathrm{s}}=\frac{W_{\mathrm{s}}-W_{\mathrm{d}}}{W_{\mathrm{d}}} \cdot 100$

where $W_{\mathrm{s}}$ is the weight of swollen polymer and $W_{\mathrm{d}}$ is the weight of dry polymer.

\section{Results and discussions}

\subsection{Mechanism of hydrogels formation}

Polyacrylamide grafted gum ghatti was synthesized in a hot air oven at $60^{\circ} \mathrm{C}$. APS is a thermal initiator and decomposed under heat leads to the formation of sulphate ion radicals (Figure 1). The sulphate ion radical formed from homolytic cleavage of initiator reacts with water and gives rise to hydroxyl free radical [28]. The free radicals also generated on the polar $-\mathrm{OH}$ groups of the gum ghatti backbone. The 


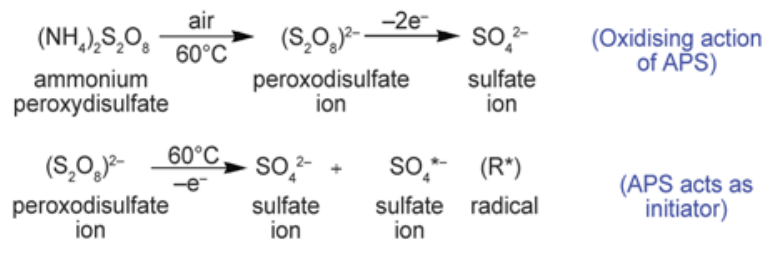

Figure 1. Generation of primary radicals under heat

monomer molecules, which are in close vicinity of the reaction sites, become acceptor of gum ghatti radicals resulting in the chain initiation and thereafter themselves become a free radical donor to neighboring molecules $[29,30]$. During chain propagation crosslinker end groups may react with the polymer chain. The copolymer formed in this way consisted of a crosslinked structure [30]. Various authors reported free radical copolymerization of vinyl monomers with carbohydrate polymers using peroxydisulfate, a chain mechanism is involved due to the formation of sulphate ion radicals, which are well known ion chain carriers for the graft copolymerization [26, 31-33].

The semi-IPN network will serve effectively as a medium for the graft copolymerization of aniline monomer in the presence of the MBA and APS as a crosslinker initiator system. At the same time peroxysulfate stimulus the oxidative polymerization reaction of aniline via a medium of cationic radicals and form PANI and PANI radicals (Figure 2) [31,<smiles>CC(C)c1ccc([NH3+])cc1</smiles><smiles></smiles><smiles>Nc1ccccc1</smiles><smiles>C[10CH3]</smiles><smiles>Cc1ccccc1N</smiles><smiles>Oc1cccc(Nc2ccc(Nc3cccc(Nc4ccccc4)c3)cc2)c1</smiles>

Figure 2. Formation of polyaniline ion radicals under heat 


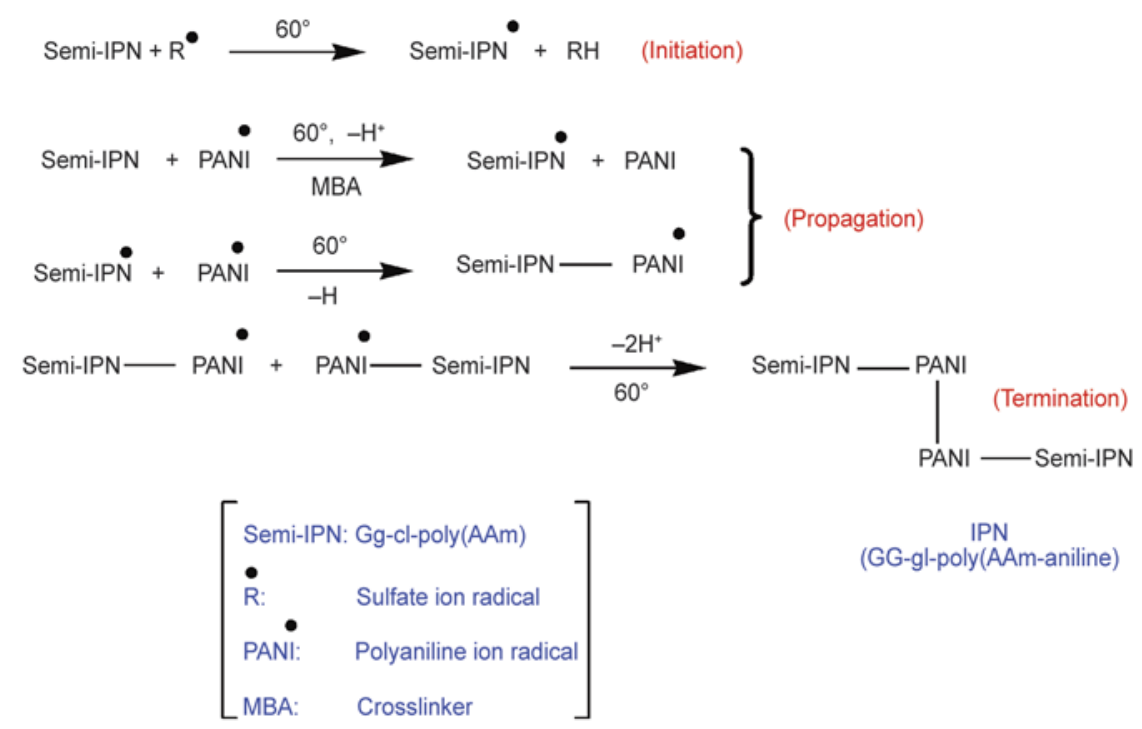

Figure 3. Formation of conducting Gg-cl-poly(AAm-ipn-aniline)

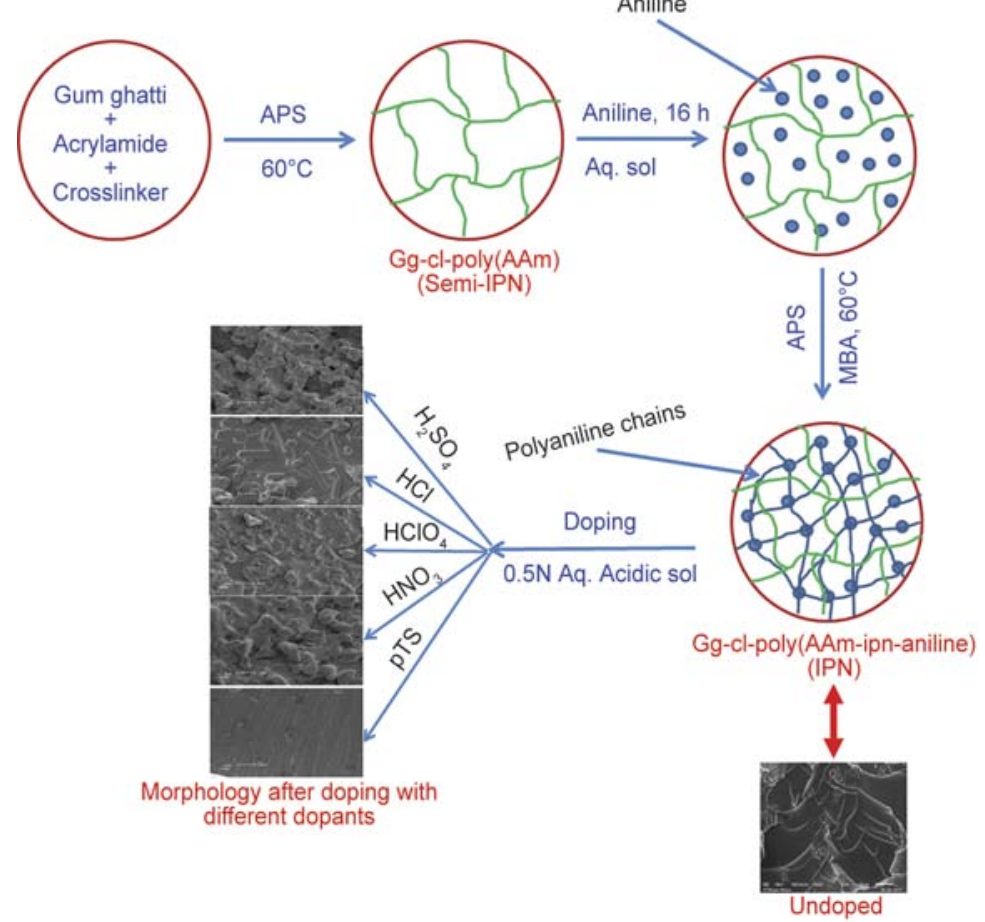

Figure 4. Schematic representation of preparation of Gg-cl-poly(AAm-ipn-aniline) hydrogels

34]. When a fully swollen semi-IPN is put in the aqueous aniline solution for $16 \mathrm{~h}$, there occurs a form of loosely bound network between the semiIPN and aniline monomer. Finally Semi-IPN radical and PANI cation radicals are combined to form Gg-cl-poly(AAm-ipn-aniline) graft copolymer. Sulfate ion is the primary radicals, generated from the APS by the reduction of one electron as shown in Figure 1. Simultaneously, APS generated sulfate ion radical by the reduction of two electrons and act as oxidant. They initiate the oxidative polymerization of aniline. The macro radical semi-ipn* may be generated by the abstraction of $\mathrm{H}$ by the growing PANI ion radical in the acidic medium, which may add onto the semi-ipn macro radicals generating new radical semi-IPN* and these chains will be grow and combined with other semi-IPN* chains to give a graft copolymer (Figure 3) [26, 31]. Preparation of Gg-cl-poly(AAm-ipn-aniline) conducting hydrogel is schematically displayed in Figure 4. 


\subsection{Optimization of different reaction parameters for the synthesis of semi-IPN [Gg-cl-poly(AAm)]}

In order to get the crosslinked hydrogel with maximum swelling capacity, the different reaction parameters such as initiator, crosslinker and monomer concentration, reaction time, amount of solvent, $\mathrm{pH}$ and reaction temperature were optimized (Figure 5). It was observed that the APS/MBA system could effectively be used to crosslink AAm onto Gum ghatti and maximum percentage swelling (857\%) was observed with APS, AAm and MBA concentration of $0.131 \cdot 10^{-1}, 1.971$ and $0.162 \cdot 10^{-1} \mathrm{~mol} \cdot \mathrm{L}^{-1}$, respectively. The optimized reaction time was found to be 210 minutes.

Here it is observed that an increase in the concentration of the initiator led to a decrease in the swelling of the superabsorbent (Figure 5a). This is due to the fact that the increase in initiator concentration resulting in an increased number of free radicals led to a terminating step by initiating a bimolecular collision [35] and decreasing molecular weight of the candidate superabsorbent [36], so both results in shortening of the polymer chains and reducing the available free volumes within the hydrogel.

Reaction time was found to possess an important role in getting the synthesized samples with higher water absorbency. However, after attaining the optimum reaction time further increment resulted in a decreased percentage swelling (Figure 5b), which again could be due to excessive crosslinking resulting in more compactness and rigidity [37].

Other optimized parameters such as reaction solvent, $\mathrm{pH}$ and temperature were found to be $12 \mathrm{~mL}$, 7.0 and $60^{\circ} \mathrm{C}$ respectively (Figure $5 \mathrm{c}-5 \mathrm{e}$ ). In the case of the reaction medium different controlling phenomenon was found to play an important role in deciding the reaction volume dependent swelling of the synthesized samples. The maximum swelling of crosslinked superabsorbent was observed with a $12 \mathrm{~mL}$ solvent (Figure $5 \mathrm{c}$ ). However, further increase in the amount of solvent results in increasing concentrations of hydroxyl radicals which finally leads to the termination of the chains. Since the absorbency
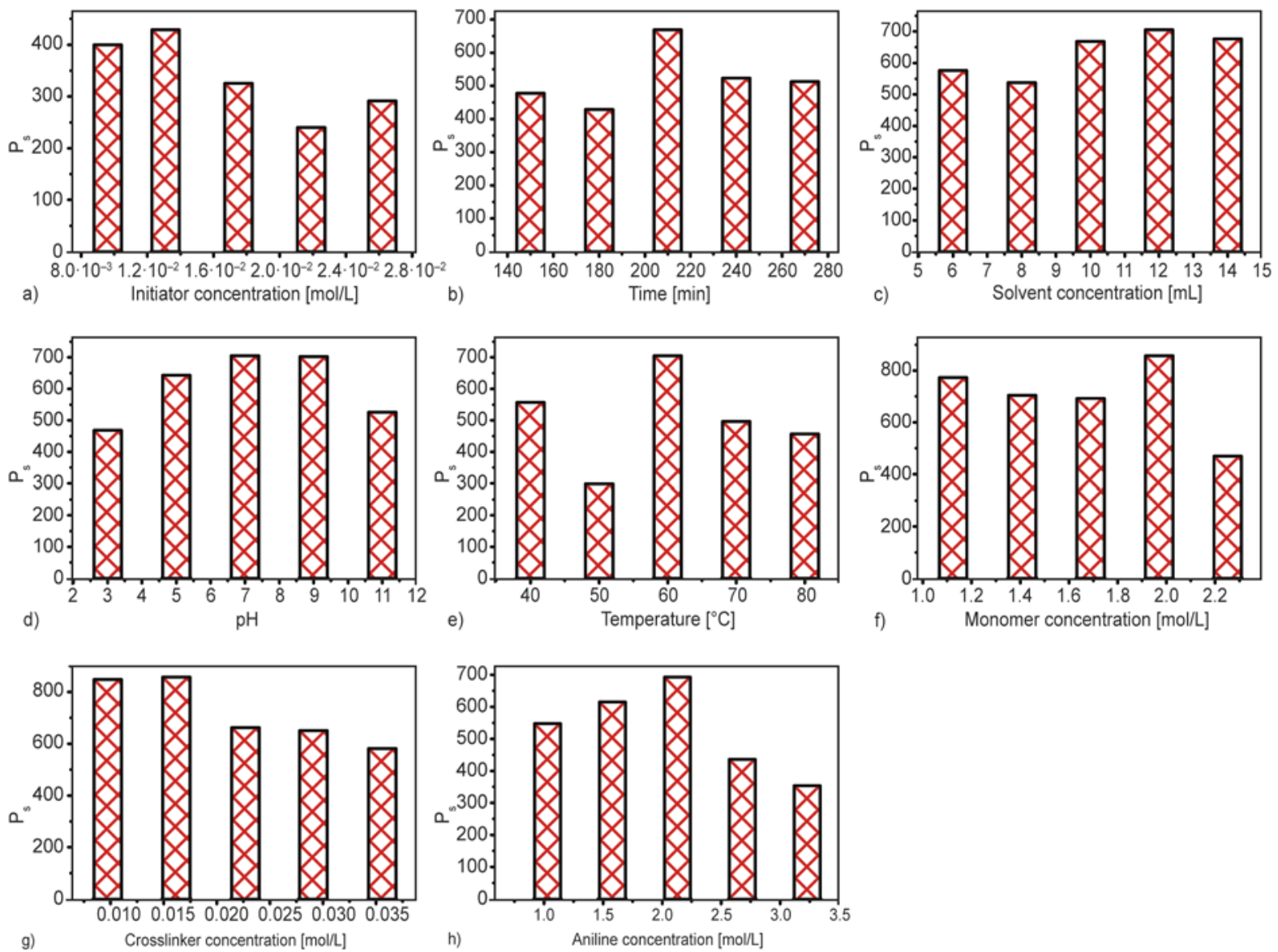

Figure 5. Variation of percentage swelling with (a) initiator concentration, (b) reaction time, (c) solvent concentration, (d) $\mathrm{pH}$, (e) temperature, (f) monomer concentration, (g) amount of crosslinker, and (h) amount of aniline 
of the superabsorbent is strongly influenced by the ionic strength therefore, no additional ions were added to the medium (through buffer solution) for setting the $\mathrm{pH}$. The equilibrium swelling was studied for $\mathrm{pH}$ from 3.0 to 11.0 using $\mathrm{NaOH}$ stock solution (Figure 5d). Maximum $P_{\mathrm{s}}(857 \%)$ was observed in the neutral medium whereas, a lesser $P_{\mathrm{s}}$ was found in acidic as well as in the alkaline media. The minimum swelling occurred in the hydrogel prepared in the highly acidic medium having a $\mathrm{pH}$ of 3 to 5 . Which might be due to the fact that the $\mathrm{NH}_{2}$ groups of acrylamide being present along the macromolecular chains in the hydrogel remained almost unionized [38], thus resulting in almost nil osmotic swelling pressure inside the hydrogel [39]. It was observed that hydrogel prepared in neutral a medium showed maximum swelling because the degree of protonation in acrylamide increased and $\mathrm{NH}_{2}$ ions get converted to $\mathrm{NH}_{3}{ }^{+}$ions that resulted in a more hydrophilic polymer network and contributed to the higher water uptake [40]. When the $\mathrm{pH}$ was changed to basic, dissociation of $-\mathrm{NH}_{2}$ group is almost complete but a very high concentration of $\mathrm{Na}^{+}$and $\mathrm{OH}^{-}$ions lead to the reduction of $P_{\mathrm{s}}$. The highest concentration of $\mathrm{Na}^{+}$ions acted as a screening bar hence a lesser $P_{\mathrm{s}}$ was observed [41] (Figure 5d).

It has been observed that the water absorbency of the hydrogels increased significantly with increasing the reaction temperature from 40 to $60^{\circ} \mathrm{C}$ (Figure $5 \mathrm{e}$ ). Furthermore, an increase in the reaction temperature lead to degradation of the carbon chain by sulphate radicals generated due to the decomposition of APS. The decomposition of APS also gave $\mathrm{O}_{2}$ radical scavenger which reacted with free radicals which lead to less hydrogel formation [42]. Additionally high temperature also leads to the fastest chain termination and chain transfer reactions.

Similarly with the increase in AAm concentration beyond the optimum level gave rise to favored homopolymerization over graft copolymerization and also caused the self-cross-linking phenomenon [35] and cross-linker concentration though gave rise to a medium stable product but increased crosslinking resulted in a rigid and compact structure with decreased swelling capacity [36] (Figure 5f). Crosslinker could prevent the dissolution of hydrophilic polymer chains in aqueous medium and increased the dimensional stability. Therefore, the significance of the optimization was to get the synthesized product with maximum water absorbance capacity along with good dimensional stability.

Semi-IPN with a varying amount of crosslinker in the $0.0972 \cdot 10^{-1}$ to $0.356 \cdot 10^{-1} \mathrm{~mol} \cdot \mathrm{L}^{-1}$ ranges were synthesized and swelling capacity in distilled water was investigated. The results, as shown in the Figure $5 \mathrm{~g}$, indicate that as the concentration of crosslinker increases from $0.0972 \cdot 10^{-1}$ to $0.162 \cdot 10^{-1} \mathrm{~mol} \cdot \mathrm{L}^{-1}$, the swelling capacity of the resulting hydrogel increased. However, a further increase in the crosslinker concentration decreased the swelling capacity. The higher concentration of crosslinker resulted in the enhancement in degree of crosslinking which in terms decreased in flexibility of the macromolecular chains [43]. This hindered the chain relaxation process, thus causing a decrease in the swelling capacity. This behavior can also be explained in terms of the reduction in gelation time with the increase in the crosslinker concentration. At higher crosslinker concentration, the gelation time was so short that bubbles formation did not occur in the proper manner, due to an increase viscosity of the gelation medium. In this way the extent of porosity decreased in the resulting hydrogel which lead to the lowering of swelling capacity.

After the optimization of different reaction parameters for the formation of semi-IPN in the hot air oven, the replications carried-out for the reproducibility of the results were in triplicates and the statistics of the results obtained was performed using the Statistical Package for Social Science (SPSS) version 10. Statistical results of the optimum percent grafting and percent swelling are depicted in Table 1.

\subsection{Optimization of aniline concentration for the synthesis of Gg-cl-poly(AAm-ipn-PANI)}

The effect of the aniline concentration was studied at different concentrations keeping other influential factors constant. It has been observed that with initial increases in aniline concentration, there was an increase in percentage swelling. However, after reaching the maxima, further increase in aniline concentration resulted in decreased swelling capacity of the synthesized sample (Figure 5h). This could be due to the more compactness, decreased pore size and formation of PANI homopolymer, giving rise to decreased water absorbency [31]. 


\subsection{FTIR spectroscopy}

The crosslinking was determined on the basis of IR spectrum of gum ghatti, Gg-cl-poly(AAm) and Ggcl-poly(AAm-aniline) (Figure 6). The gum ghatti showed broad peaks at 3434 and $1032 \mathrm{~cm}^{-1}$, characteristics of the saccharide structure (due to $-\mathrm{OH}$ stretching) [44]. The peaks at 2925 and $1622 \mathrm{~cm}^{-1}$ was assigned to the stretching vibration of the $-\mathrm{CH}$ group and $-\mathrm{C}=\mathrm{O}$ stretching of a carbonyl group respectively [30]. Another characteristic peak of the acid group was found at $1422 \mathrm{~cm}^{-1}$ due to $-\mathrm{OH}$ bending. After gum ghatti had been grafted copolymerized with acrylamide, broad peaks were observed at 1658 and $1456 \mathrm{~cm}^{-1}$ contributing to the $\mathrm{C}=\mathrm{O}$ stretching of amide I band and $-\mathrm{NH}$ in plane bending of amide II respectively [21, 22]. Interestingly, the peaks after grafting shifted to a higher wavenumber region indicating the formation of crosslinked hydrogel. On the other hand FTIR spectrum of Ggcl-poly(AAm-ipn-aniline) illustrated the characteristics peaks of PANI, as well as Gg-cl-poly(AAm)

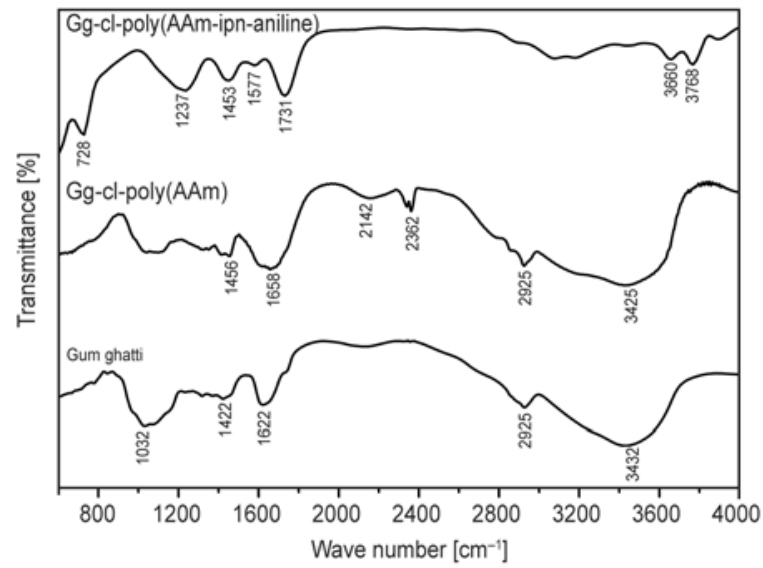

Figure 6. FTIR spectra of (a) Gum ghatti, (b) Gg-cl-poly (AAm) and (c) Gg-cl-poly(AAm-ipn-aniline)

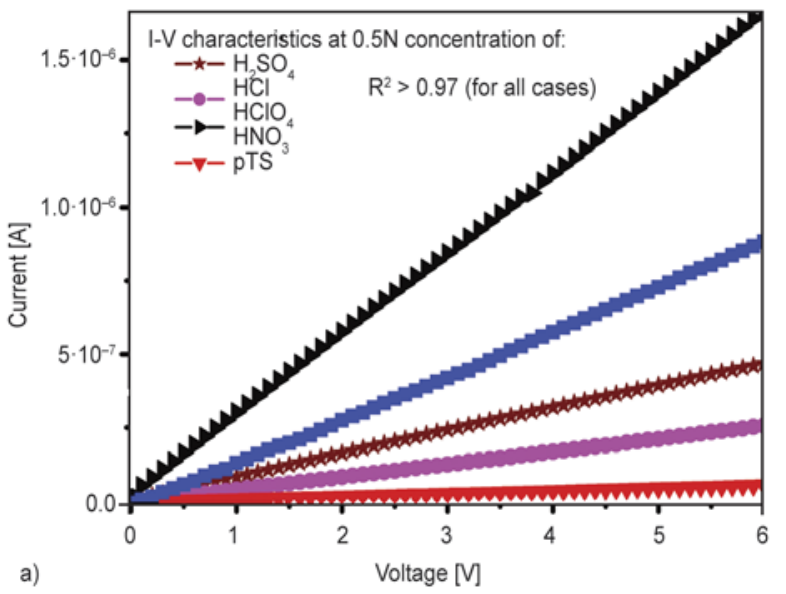

$[30,45]$. The bands at 1496 and $1574 \mathrm{~cm}^{-1}$ represent the benzoid and quinoid ring vibration of PANI, respectively. Conducting form of PANI is described by band at $1237 \mathrm{~cm}^{-1}[10,46]$. The bands at 796 and $1731 \mathrm{~cm}^{-1}$ were corresponding to an out-of-plane bending vibration of $\mathrm{C}-\mathrm{H}$ on para-disubstituted rings and carboxyl groups, respectively $[10,47$, 48]. It has been reported that the band at $1110 \mathrm{~cm}^{-1}$ to be a measure of the degree of the delocalization of electrons and is also revealing of high conductivity. The shifting and formation of new bands (728, 3660 and $3768 \mathrm{~cm}^{-1}$ ) supported the formation $\mathrm{Gg}$ cl-poly(AAm-aniline) hydrogel. Thus, it is quite evident from FTIR studies that grafted chains of AAm and aniline got grafted onto gum ghatti.

\subsection{Current-voltage characteristics}

The current-voltage (I-V) curve of the IPN samples at room temperature was measured using a twoprobe method. The I-V relationships of the IPN sample with $0.5 \mathrm{~N}$ concentrations of each dopant are shown in Figure 7a, which shows an ohmic behavior. The nature of the dopants significantly influenced the conductivity. The differences in I-V characteristics were due to the effect of the dopant ions. It was found that $\mathrm{HClO}_{4}$ doped IPN showed a maximum current, which pointed to the maximum conductivity (Table 2). Various authors reported the synthesis of PANI by using different dopants and its characterization [49, 50]. Kulkarni et al. [51] synthesized PANI by chemical polymerization using different inorganic acids, such as $\mathrm{HCl}, \mathrm{H}_{2} \mathrm{SO}_{4}, \mathrm{HClO}_{4}$, and $\mathrm{HNO}_{3}$, as protonic acid media. They have reported a maximum conductivity for $\mathrm{HClO}_{4}$ doped PANI sample.

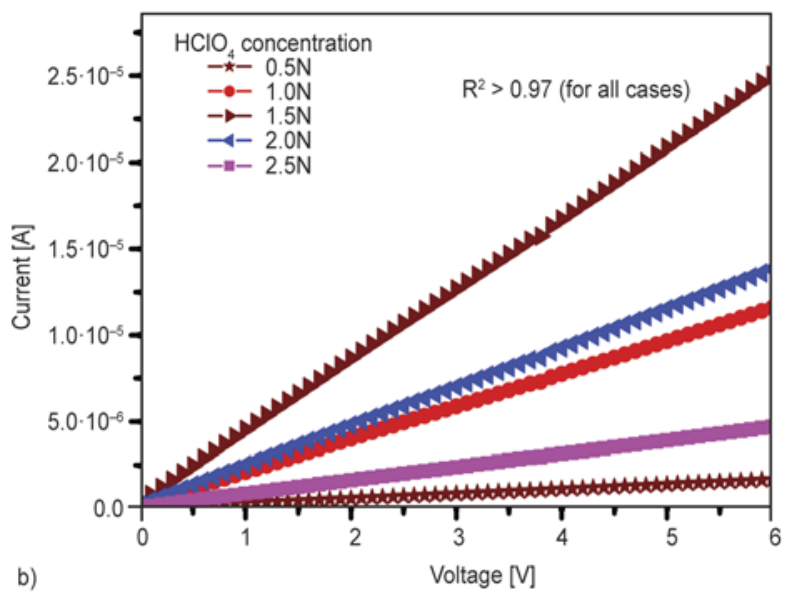

Figure 7. Current-voltage plots for IPN hydrogel with (a) different dopants and (b) as a function of perchloric acid concentration 
Table 2. Room-temperature conductivities of IPN hydrogel doped with different acids

\begin{tabular}{|l|c|}
\hline \multicolumn{1}{|c|}{ Hydrogels } & $\begin{array}{c}\text { Conductivity } \\
\text { [S/cm] }\end{array}$ \\
\hline Gg-cl-poly(AAm-ipn-aniline)- $\mathrm{H}_{2} \mathrm{SO}_{4}$ & $0.15 \cdot 10^{-7}$ \\
\hline Gg-cl-poly(AAm-ipn-aniline)-HCl & $0.80 \cdot 10^{-7}$ \\
\hline Gg-cl-poly(AAm-ipn-aniline)- $\mathrm{HClO}_{4}$ & $0.50 \cdot 10^{-6}$ \\
\hline Gg-cl-poly(AAm-ipn-aniline)- $\mathrm{HNO}_{3}$ & $0.10 \cdot 10^{-8}$ \\
\hline Gg-cl-poly(AAm-ipn-aniline)-pTS & $0.20 \cdot 10^{-7}$ \\
\hline
\end{tabular}

Taking this into account the IPN samples were further doped with different concentration of $\mathrm{HClO}_{4}$ varying from $0.5-2.5 \mathrm{~N}$ (Figure $7 \mathrm{~b}$ ). The improvement in the electrical conductivity with increasing $\mathrm{HClO}_{4}$ concentration was due to increasing the degree of protonation of the imine group of PANI in the IPN. However, a decrease in electrical conductivity occurred at higher $\mathrm{HClO} 4$ concentrations (2.0$2.5 \mathrm{~N})$. This may be probably due to the over protonation of PANI chains causing a decrease in the delocalization length of PANI and hindrance in the amount of the electrons between the valence band and the conduction band. The maximum conductivity was observed at a $1.5 \mathrm{~N} \mathrm{HClO}_{4}$ concentration. Various authors reported the synthesis of conducting hydrogels with different materials [3, 5-7, 52].

\subsection{Surface morphology}

The surface morphology of the gum ghatti and its amalgamated structures are shown in (Figure 8) in three states the native, cross linked and layered/ hybrid with polyaniline (undoped). The pure gum ghatti showed a smooth surface as shown in Figure $8 \mathrm{a}-8 \mathrm{~b}$. The film is also covered with white spots uniformly distributed over the whole surface [29, 30]. After the cross linking of gum ghatti with poly (AAm), the structural morphology gets changed and resembles an whisker like morphology with a rough agglomerated surface (Figure $8 \mathrm{c}-8 \mathrm{~d}$ ). These figures display the favorable cross linking network between gum ghatti and poly(AAm). Gg-cl-poly (AAm-ipn-aniline) hydrogel form a heterogeneous network type structure, as shown in Figure 8e-8f. The three micrographs and their magnified images clearly show the variation in chemical structures and change in surface morphology in the cross linked networks. Figure 9 shows SEM micrographs of Gg-cl-poly (AAm-ipn-aniline) doped with $\mathrm{H}_{2} \mathrm{SO}_{4}, \mathrm{HCl}, \mathrm{HClO}_{4}$, $\mathrm{HNO}_{3}$ and pTS. The morphology of the IPN samples was changed based on the type of acid used to dope. As shown in the SEM images of Figure 9,
IPN samples with varying dopants exhibit varying microstructures. It was observed that the type of dopants has considerable influence on the properties-in particular, electrical and morphological features of the resulting IPN hydrogel. Each acid produced characteristic morphology. It is well documented that the incorporation of dopant ions modifies the polymer lattice, which leads to the ionization of sites in the chains which in terms creates defects in the chain [53]. The formation of defects due to the dopant ions provide the mobility of the charge carriers on which conduction depends. Moreover, the conductivity is also dependent on the number of charge carriers. The morphological studies reveal some interesting features as a function of protonic acid used during synthesis.

Figure $9 \mathrm{a}-9 \mathrm{~b}$ shows the $\mathrm{H}_{2} \mathrm{SO}_{4}$ doped IPN showing agglomerated particles type morphology with different shapes and noticeable pores which can be useful for chemical sensing applications. The $\mathrm{HCl}$ doped sample has flat-faced particles of varied shapes and sizes (Figure 9c-9d); the $\mathrm{HClO}_{4}$ doped sample (Figure 9e-9f) has a rough surface with noticeable pores. Figure $9 \mathrm{~g}-9 \mathrm{~h}$ shows the loose flaky structures of the $\mathrm{HNO}_{3}$-doped IPN hydrogel. Lastly, Figure $9 \mathrm{i}-9 \mathrm{j}$ shows the rough surface of the pTS doped sample. The low conductivity of the $\mathrm{HNO}_{3}$-doped sample may be due to these loose flaky structures and presence of air space. Thus, SEM analysis reveals the variation in the surface morphologies of the undoped and doped IPN hydrogel. Finally, it can be concluded that the surface morphology and the conductivity of the resulting IPN hydrogel can be tuned by varying the types of dopant.

\subsection{X-ray diffraction studies}

XRD patterns of the samples are characterized by halos extending in the $2 \theta$ range $10-60^{\circ}$. XRD pattern of gum ghatti showed that the gum ghatti is partly crystalline with a dominant amorphous phase while on poly(AAm) grafting, the graft copolymer acquires more amorphous area (Figure 10). Change in the XRD pattern confirms the grafting. In the graft copolymer the decrease in the diffraction intensity and an increase in the broadness was due to the presence of poly(AAm) grafts at gum ghatti, which was also confirmed by changes in the surface morphology as seen from SEM micrographs (Figure 8a8f). Gum ghatti showed peaks at 19.740 and 360 with relative intensities of 462 and 257, respectively. 


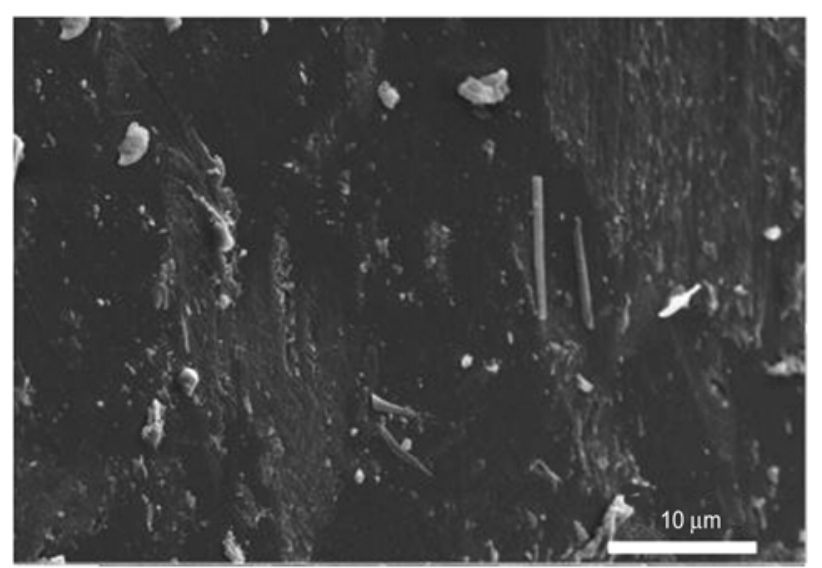

a)

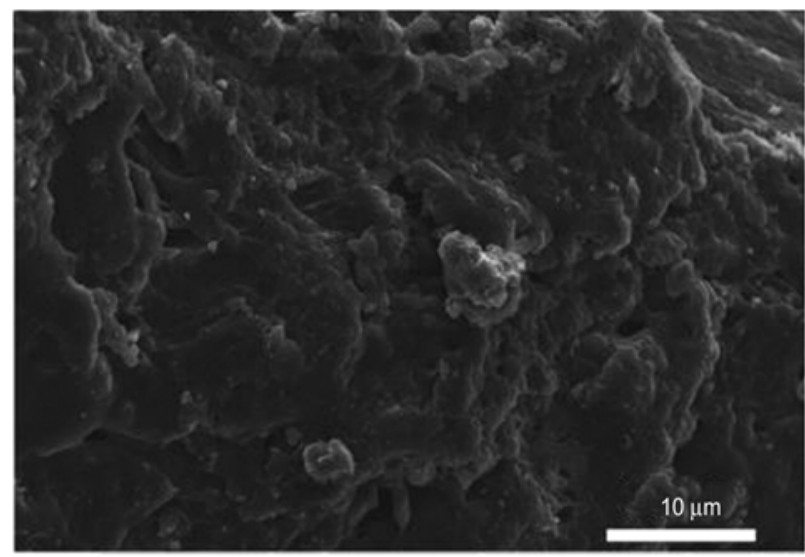

c)

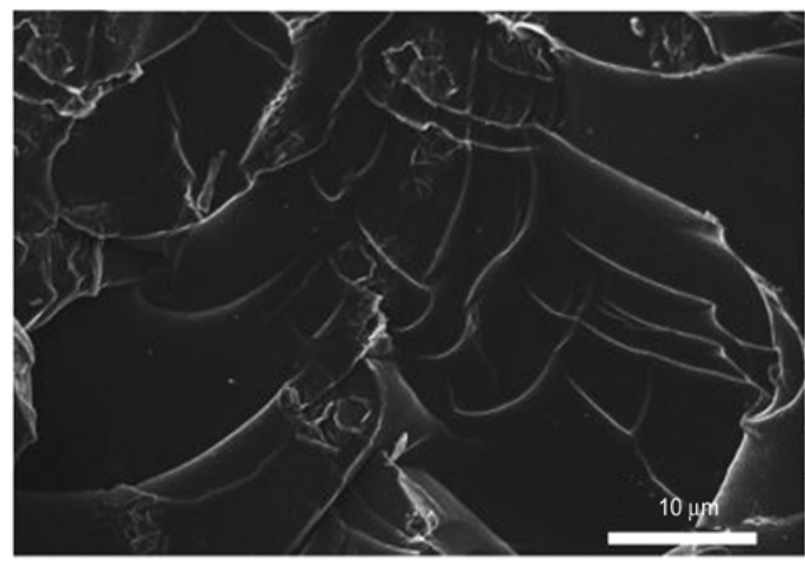

e)

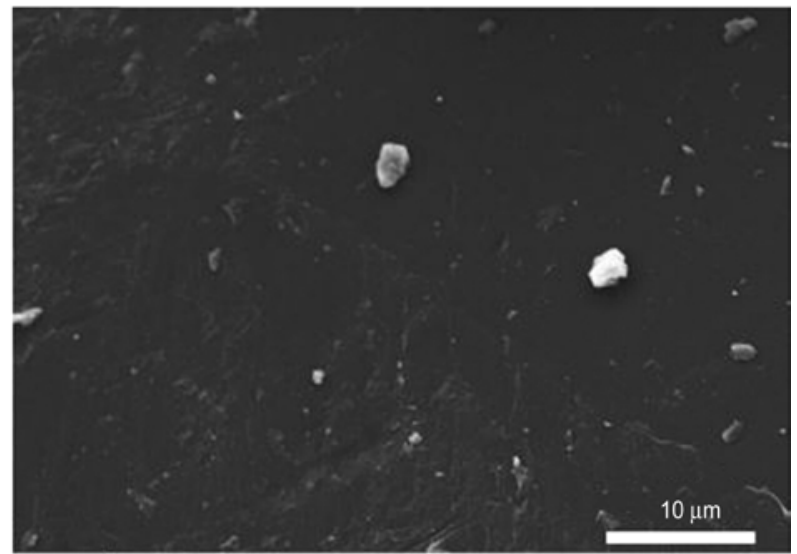

b)

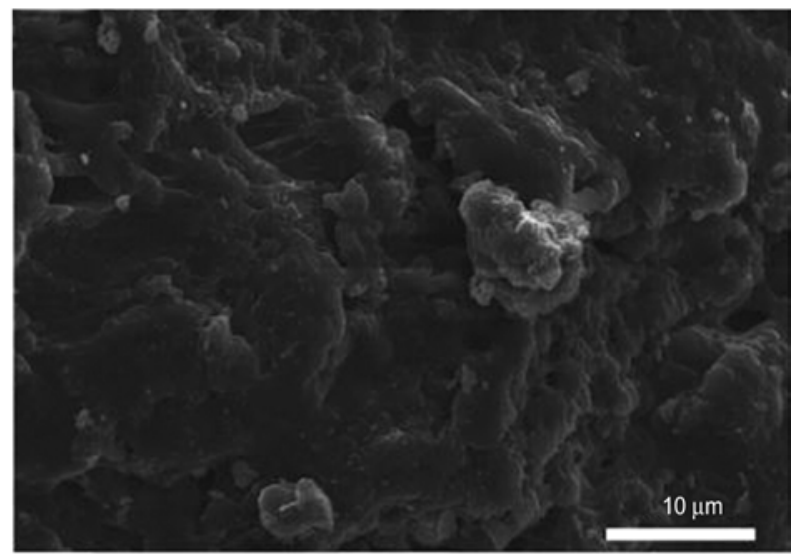

d)

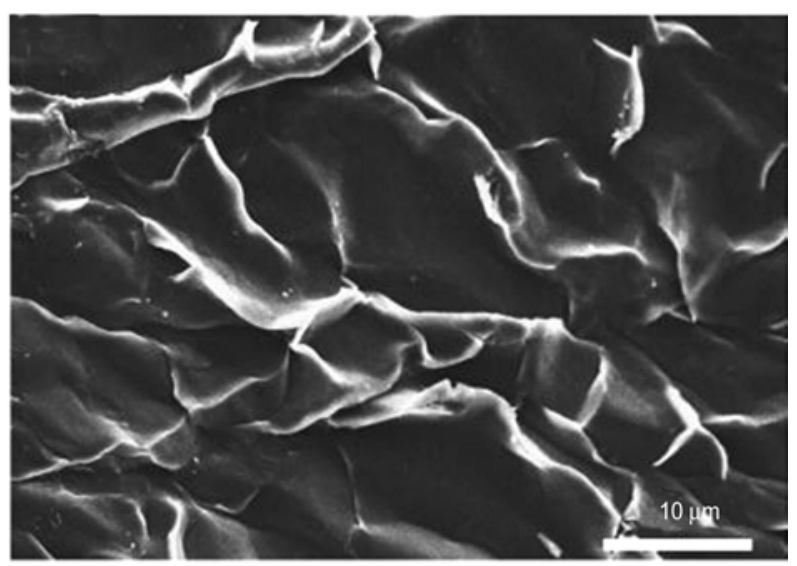

f)

Figure 8. Scanning electron micrographs of (a-b) Gum ghatti, (c-d) Gg-cl-poly(AAm), and (e-f) undoped Gg-clpoly(AAm-ipn-aniline)

However, Gg-cl-poly(AAm) showed peaks at 22 and $35.4^{\circ}$ with relative intensities of 289 and 150 , respectively. It is interesting to note that the intensity of the diffraction peaks increased with a cross linked network on moving from Gg-cl-poly (AAm) to Gg-cl-poly (AAm-ipn-aniline), which indicated the enhancement in crystallinity [30, 44]. This enhancement in crystallinity could be attributed to the interaction of PANI chains in the crosslinked network of Gg-cl-poly(AAm) [54]. The PANI chains crosslinked with each other during the polymerization process to form a network structure [30]. This phenomenon relates the changes in the surface morphology revealed by SEM images. Thus, the XRD patterns of the crosslinked hydrogels provide an additional evidence of AAm and PANI crosslinking onto gum ghatti. 


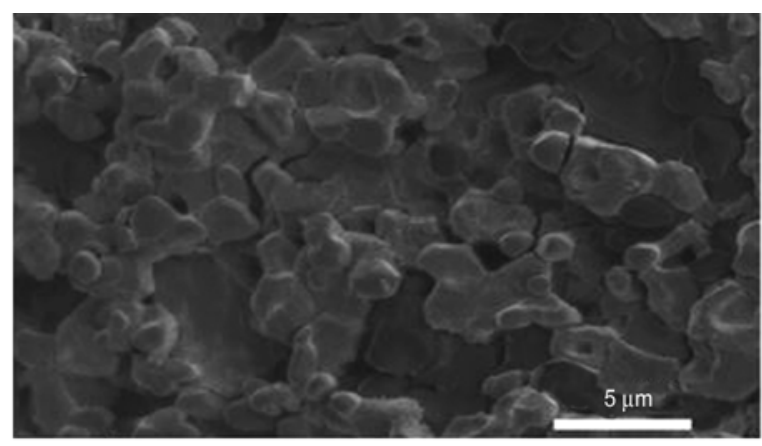

a)

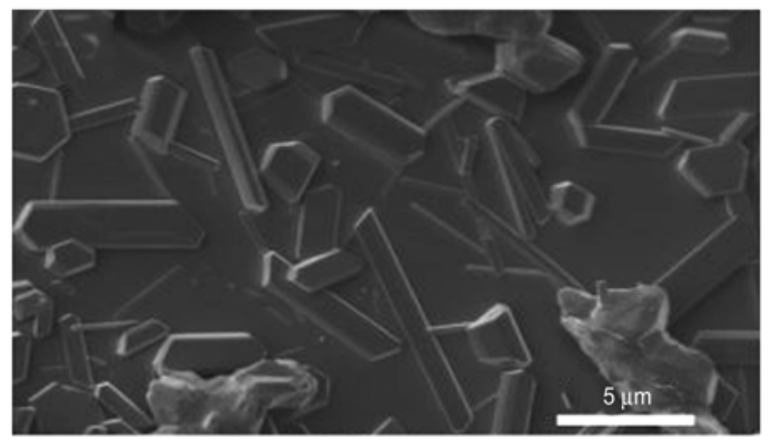

c)

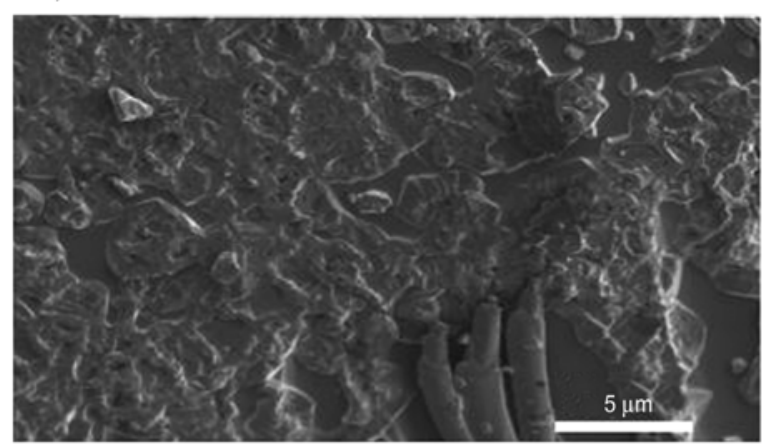

e)

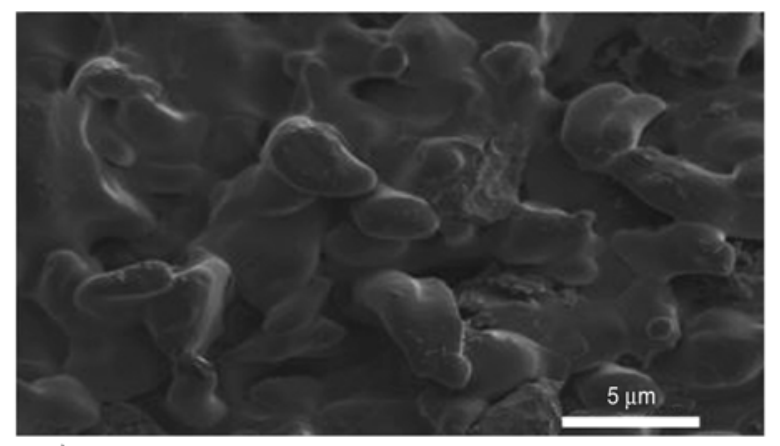

g)

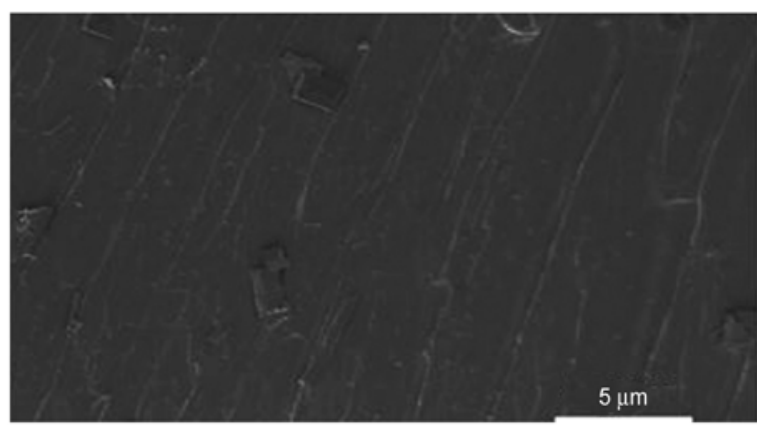

i)

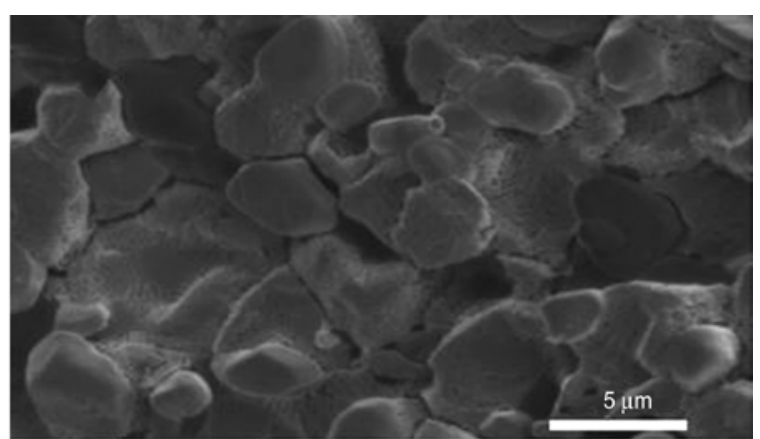

b)

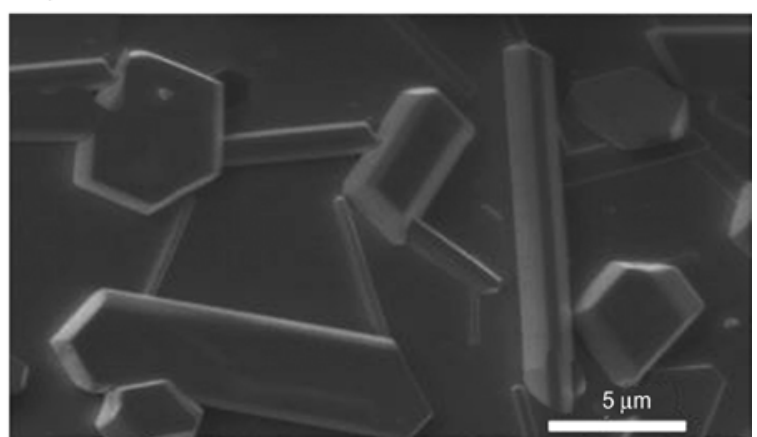

d)
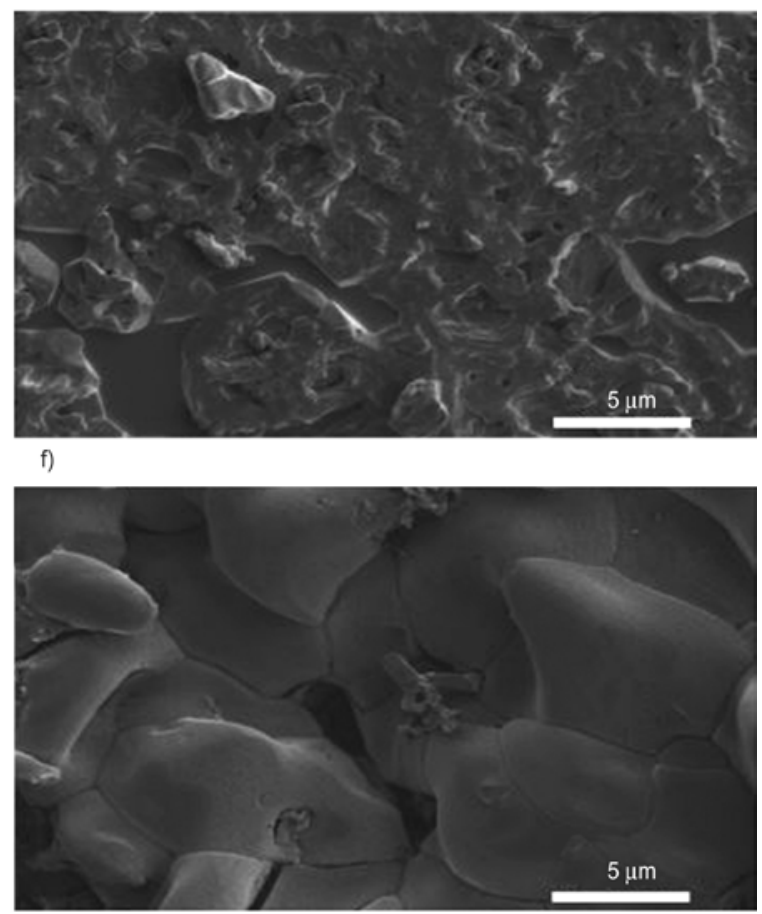

h)

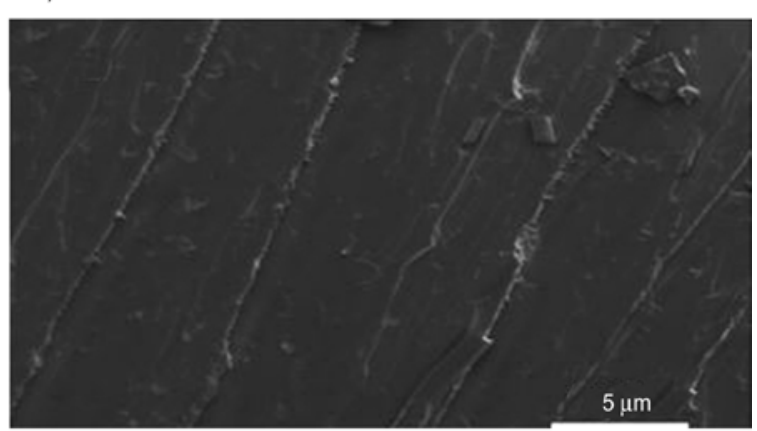

Figure 9. Scanning electron micrographs of IPN samples doped with (a-b) $\mathrm{H}_{2} \mathrm{SO}_{4}$, (c-d) $\mathrm{HCl}$, (e-f) $\mathrm{HClO}_{4}$, (g-h) $\mathrm{HNO}_{3}$ and (i-j) pTS 


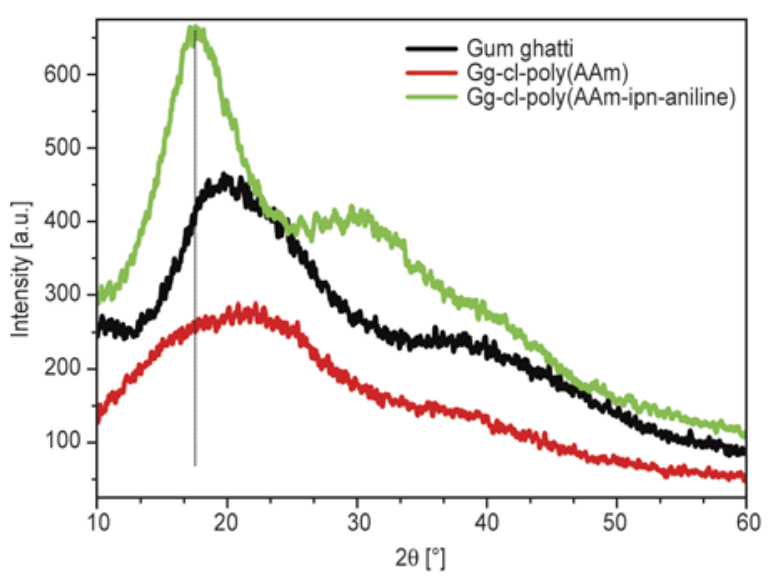

Figure 10. XRD patterns of the Gum ghatti, Gg-cl-poly (AAm) and Gg-cl-poly(AAm-ipn-aniline)

\subsection{Thermal analysis}

The effect of crosslinking of poly(AAm) and poly (AAm-aniline) on the thermal stability of gum ghatti was studied with the help of the thermogravemetric technique (Figure 11). Grafting is clear from the TGA that the Gg-cl-poly(AAm-ipn-aniline) has more thermal stability than the gum ghatti and Gg-clpoly(AAm) both [26]. The percent of weight losses at the selected temperatures are listed in Table 3. TGA of $G_{\mathrm{g}}$ showed two-stage decomposition. $G_{\mathrm{g}}$ exhibited initial decomposition temperature (IDT) at $207^{\circ} \mathrm{C}$ and final decomposition temperature (FDT) at $534^{\circ} \mathrm{C}$ [44]. Whereas, Gg-cl-poly(AAm) showed

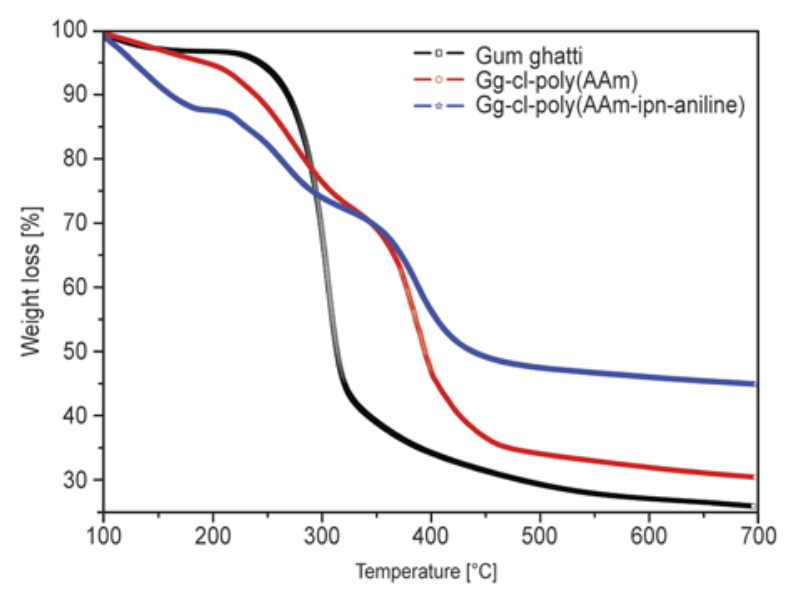

Figure 11. TGA spectra of Gum ghatti, Gg-cl-poly(AAm) and Gg-cl-poly(AAm-ipn-aniline)
IDT at $190^{\circ} \mathrm{C}$ and $\mathrm{FDT}$ was at $578^{\circ} \mathrm{C}$. It was found that the IDT of $G_{\mathrm{g}}$ was higher whereas, the FDT was lower than that of Gg-cl-poly(AAm). The TGA spectrum of IPN shows three-step degradation. The first step degradation was due to the loss of moisture or water content, which ends at $180^{\circ} \mathrm{C}$ [55]. The second weight (28\%) loss at temperature between 211 and $320^{\circ} \mathrm{C}$ is believed to be due to the elimination of some low molecules or due to dopant evolution. The third stage decomposition started at about $340^{\circ} \mathrm{C}$ is assigned to the breakdown of the IPN structure. Thus, it is clear from the thermo gravimetric analysis studies that the synthesized IPN was found to posses higher thermal stability with higher decomposition temperature in comparison to gum ghatti and semi-IPN Gg-cl-poly(AAm). Thus, good thermal stability coupled with high electrical conductivity is the most significant advantage of dopants for the synthesis of conducting IPN hydrogels. This enhanced thermal stability of the grafted hydrogel networks might be due to the formation of crosslinks between different polymeric chains through covalent bonding.

\section{Conclusions}

In summary we have investigated the effects of dopants on the surface morphologies and electrical conductivity of the IPN hydrogels. It was found that the surface morphology and electrical conductivity strongly depended on the type of dopants. These results indicate that the present work may open a new way to synthesize IPN structures with different surface morphologies and conductivities. Further, thermogravemetric analysis showed good thermal stability for the IPN hydrogel. The hydrogels based on biodegradable natural gum ghatti significantly improved the swelling capacity, which can be used as promising water holding materials for agricultural and biomedical applications. Further studies in the direction of controlled drug delivery of crosslinked hydrogels are under progress in order to extend the application of these hydrogels in biomedical applications.

Table 3. Details of $\%$ weight loss at different temperatures

\begin{tabular}{|c|c|c|c|c|c|c|c|c|c|}
\hline \multirow{2}{*}{ Sample name } & \multirow{2}{*}{$\begin{array}{l}\text { IDT } \\
{\left[{ }^{\circ} \mathbf{C}\right]}\end{array}$} & \multirow{2}{*}{$\begin{array}{l}\text { FDT } \\
{\left[{ }^{\circ} \mathrm{C}\right]}\end{array}$} & \multicolumn{7}{|c|}{ Weight loss [\%] at different temperature } \\
\hline & & & $250^{\circ} \mathrm{C}$ & $300^{\circ} \mathrm{C}$ & $350^{\circ} \mathrm{C}$ & $400^{\circ} \mathrm{C}$ & $450^{\circ} \mathrm{C}$ & $500^{\circ} \mathrm{C}$ & $600^{\circ} \mathrm{C}$ \\
\hline Gg & 207 & 534 & 5.8 & 32.3 & 61.2 & 65.8 & 69.7 & 70.7 & 73 \\
\hline Gg-cl-poly(AAm) & 190 & 578 & 12.0 & 23.7 & 30.7 & 53.3 & 63.2 & 66.0 & 68 \\
\hline Gg-cl-poly(AAm-ipn-aniline) & 100 & 600 & 18.0 & 26.0 & 30.7 & 43.7 & 51.0 & 52.7 & 54 \\
\hline
\end{tabular}




\section{Acknowledgements}

The research is supported by the South African Research Chairs Initiative of the Department of Science and Technology and National Research Foundation of South Africa. The University of the Free State Cluster program for financial support. Authors are also thankful to department of Chemistry, University of the Free State for providing TGA spectra.

\section{References}

[1] Fan S., Tang Q., Wu J., Hu D., Lin J.: Two-step synthesis of polyacrylamide/poly(vinyl alcohol)/polyacrylamide/graphite interpenetrating network hydrogel and its swelling, conducting and mechanical properties. Journal of Materials Science, 43, 5898-5904 (2008). DOI: $10.1007 / \mathrm{s} 10853-008-2855-\mathrm{Z}$

[2] Pissis P., Kyritsis A.: Electrical conductivity studies in hydrogels. Solid State Ionics, 97, 105-113 (1997). DOI: $10.1016 / \mathrm{S} 0167-2738(97) 00074-\mathrm{X}$

[3] Tiwari A.: Synthesis and characterization of $\mathrm{pH}$ switching electrical conducting biopolymer hybrids for sensor applications. Journal of Polymer Research, 15, 337342 (2008).

DOI: 10.1007/s10965-008-9176-4

[4] Sun X-G., Liu G., Xie J., Han Y., Kerr J. B.: New gel polyelectrolytes for rechargeable lithium batteries. Solid State Ionics, 175, 713-716 (2004).

DOI: $10.1016 /$ j.ssi.2003.11.043

[5] Lin J., Tang Q., Wu J.: The synthesis and electrical conductivity of a polyacrylamide/Cu conducting hydrogel. Reactive and Functional Polymers, 67, 489-494 (2007).

DOI: $10.1016 /$ j.reactfunctpolym.2007.02.002

[6] Lin J., Tang Q., Wu J., Hao S.: The synthesis and electrical conductivity of a polyacrylate/graphite hydrogel. Reactive and Functional Polymers, 67, 275-281 (2007). DOI: $10.1016 /$ j.reactfunctpolym.2007.01.011

[7] Tang Q., Wu J., Lin J.: A multifunctional hydrogel with high conductivity, $\mathrm{pH}$-responsive, thermo-responsive and release properties from polyacrylate/polyaniline hybrid. Carbohydrate Polymers, 73, 315-321 (2008). DOI: $10.1016 /$ j.carbpol.2007.11.036

[8] Tang Q., Wu J., Sun H., Fan S., Hu D., Lin J.: Superabsorbent conducting hydrogel from poly(acrylamideaniline) with thermo-sensitivity and release properties. Carbohydrate Polymers, 73, 473-481 (2008). DOI: $10.1016 /$ j.carbpol.2007.12.030

[9] Peppas N. A., Bures P., Leobandung W., Ichikawa H.: Hydrogels in pharmaceutical formulations. European Journal of Pharmaceutics and Biopharmaceutics, 50, 27-46 (2000).

DOI: 10.1016/S0939-6411(00)00090-4
[10] Sharma Y., Tiwari A., Hattori S., Terada D., Sharma A. K., Ramalingam M., Kobayashi H.: Fabrication of conducting electrospun nanofibers scaffold for three-dimensional cells culture. International Journal of Biological Macromolecules, 51, 627-631 (2012).

DOI: 10.1016/j.ijbiomac.2012.06.014

[11] Buenger D., Topuz F., Groll J.: Hydrogels in sensing applications. Progress in Polymer Science, 37, 16781719 (2012). DOI: 10.1016/j.progpolymsci.2012.09.001

[12] Kaith B. S., Saruchi, Jindal R., Bhatti M. S.: Screening and RSM optimization for synthesis of a Gum tragacanth-acrylic acid based device for in situ controlled cetirizine dihydrochloride release. Soft Matter, 8, 22862293 (2012). DOI: 10.1039/C2SM07033B

[13] Deshmukh A. S., Setty C. M., Badiger A. M., Muralikrishna K. S.: Gum ghatti: A promising polysaccharide for pharmaceutical applications. Carbohydrate Polymers, 87, 980-986 (2012).

DOI: $10.1016 /$ j.carbpol.2011.08.099

[14] Rana V., Rai P., Tiwary A. K., Singh R. S., Kennedy J. F., Knill C. J.: Modified gums: Approaches and applications in drug delivery. Carbohydrate Polymers, 83, 1031-1047 (2011).

DOI: $10.1016 /$ j.carbpol.2010.09.010

[15] Ghosh S., Sen G., Jha U., Pal S.: Novel biodegradable polymeric flocculant based on polyacrylamide-grafted tamarind kernel polysaccharide. Bioresource Technology, 101, 9638-9644 (2010).

DOI: $10.1016 /$ j.biortech.2010.07.058

[16] Malhotra B. D., Ghosh S., Chandra R.: Polyaniline/polymeric acid composite, a novel conducting rubber. Journal of Applied Polymer Science, 40, 1049-1052 (1990). DOI: 10.1002/app.1990.070400536

[17] Tiwari A., Sharma Y., Hattori S., Terada D., Sharma A. K., Turner A. P. F., Kobayashi H.: Influence of poly(nisopropylacrylamide)-CNT-polyaniline three-dimensional electrospun microfabric scaffolds on cell growth and viability. Biopolymers, 99, 334-341 (2013). DOI: $10.1002 /$ bip. 22170

[18] Pron A., Genoud F., Menardo C., Nechtschein M.: The effect of the oxidation conditions on the chemical polymerization of polyaniline. Synthetic Metals, 24, 193201 (1988).

DOI: 10.1016/0379-6779(88)90257-3

[19] Syed A. A., Dinesan M. K.: Review: Polyaniline - A novel polymeric material. Talanta, 38, 815-837 (1991). DOI: 10.1016/0039-9140(91)80261-W

[20] Cortés M. T., Sierra E. V.: Effect of synthesis parameters in polyaniline: Influence on yield and thermal behavior. Polymer Bulletin, 56, 37-45 (2006). DOI: $10.1007 / \mathrm{s} 00289-005-0467-1$ 
[21] Mittal H., Mishra S. B., Mishra A. K., Kaith B. S., Jindal R.: Flocculation characteristics and biodegradation studies of Gum ghatti based hydrogels. International Journal of Biological Macromolecules, 58, 37-46 (2013). DOI: $10.1016 /$ j.ijbiomac.2013.03.045

[22] Rani P., Sen G., Mishra S., Jha U.: Microwave assisted synthesis of polyacrylamide grafted gum ghatti and its application as flocculant. Carbohydrate Polymers, 89, 275-281 (2012).

DOI: $10.1016 /$ j.carbpol.2012.03.009

[23] Tiwari A., Singh V.: Synthesis and characterization of electrical conducting chitosan-graft-polyaniline. Express Polymer Letters, 1, 308-317 (2007).

DOI: $10.3144 /$ expresspolymlett.2007.44

[24] Shukla S. K., Tiwari A.: Synthesis of chemical responsive chitosan-grafted-polyaniline bio-composite. Advanced Materials Research, 306-307, 82-86 (2011) DOI: 10.4028/www.scientific.net/AMR.306-307.82

[25] Tiwari A.: Gum arabic-graft-polyaniline: An electrically active redox biomaterial for sensor applications. Journal of Macromolecular Science Part A: Pure and Applied Chemistry, 44, 735-745 (2007).

DOI: $10.1080 / 10601320701353116$

[26] Tiwari A., Singh S. P.: Synthesis and characterization of biopolymer-based electrical conducting graft copolymers. Journal of Applied Polymer Science, 108, 11691177 (2008). DOI: 10.1002/app.27789

[27] Singh V., Tiwari A., Pandey S., Singh S. K.: Peroxydisulfate initiated synthesis of potato starch-graftpoly(acrylonitrile) under microwave irradiation. Express Polymer Letters, 1, 51-58 (2007).

DOI: $10.3144 /$ expresspolymlett.2007.10

[28] Kaith B. S., Kumar K.: In air synthesis of psy-clpoly(AAm) network and its application in water-absorption from oil-water emulsions. Express Polymer Letters, 1, 474-480 (2007).

DOI: $10.3144 /$ expresspolymlett.2007.66

[29] Kaith B. S., Sharma K., Kumar V., Kumar V., Swart H. C., Kalia S.: Effects of swift heavy ion beam irradiation on the structural and morphological properties of poly(methacrylic acid) cross-linked gum ghatti films. Vacuum, 101, 166-170 (2014). DOI: $10.1016 /$ j.vacuum.2013.08.020

[30] Sharma K., Kaith B. S., Kumar V., Kumar V., Som S., Kalia S., Swart H. C.: Synthesis and properties of poly (acrylamide-aniline)-grafted gum ghatti based nanospikes. RSC Advances, 3, 25830-25839 (2013).

DOI: $10.1039 / \mathrm{c} 3 \mathrm{ra} 44809 \mathrm{f}$

[31] Tiwari A., Singh V.: Microwave-induced synthesis of electrical conducting gum acacia-graft-polyaniline. Carbohydrate Polymers, 74, 427-434 (2008).

DOI: $10.1016 /$ j.carbpol.2008.03.015
[32] Singh V., Tiwari A., Sanghi R.: Studies on $\mathrm{K}_{2} \mathrm{~S}_{2} \mathrm{O}_{8}$ / ascorbic acid initiated synthesis of Ipomoea dasysperma seed gum-g-poly(acrylonitrile): A potential industrial gum. Journal of Applied Polymer Science, 98, 16521662 (2005).

DOI: 10.1002/app.22333

[33] Singh V., Tiwari A., Shukla P., Singh S. P., Sanghi R.: Grafting of methylmethacrylate on to the plant seed galactomannans using potassium persulphate/ascorbic acid redox pair. Reactive and Functional Polymers, 66, 1306-1318 (2006).

DOI: 10.1016/j.reactfunctpolym.2006.03.013

[34] Ding Y., Padias A. B., Hall H. K. Jr.: Chemical trapping experiments support a cation-radical mechanism for the oxidative polymerization of aniline. Journal of Polymer Science Part A: Polymer Chemistry, 37, 25692579 (1999).

DOI: 10.1002/(SICI)1099-0518(19990715)37:14<2569 $\because$ AID-POLA30>3.0.CO;2-N

[35] Chen J., Zhao Y.: Relationship between water absorbency and reaction conditions in aqueous solution polymerization of polyacrylate superabsorbents. Journal of Applied Polymer Science, 75, 808-814 (2000).

DOI: 10.1002/(SICI)1097-4628(20000207)75:6<808:: AID-APP10>3.0.CO;2-3

[36] Pourjavadi A., Harzandi A. M., Hosseinzadeh H.: Modified carrageenan 3. Synthesis of a novel polysaccharide-based superabsorbent hydrogel via graft copolymerization of acrylic acid onto kappa-carrageenan in air. European Polymer Journal, 40, 1363-1370 (2004). DOI: 10.1016/j.eurpolymj.2004.02.016

[37] Athawale V. D., Rathi S. C.: Graft polymerization: Starch as a model substrate. Journal of Macromolecular Science Part C: Polymer Reviews, 39, 445-480 (1999).

DOI: $10.1081 / \mathrm{MC}-100101424$

[38] Motonaga T., Shibayama M.: Studies on pH and temperature dependence of the dynamics and heterogeneities in poly( $\mathrm{N}$-isopropylacrylamide- $\mathrm{co}$-sodium acrylate) gels. Polymer, 42, 8925-8934 (2001).

DOI: $10.1016 / \mathrm{S} 0032-3861(01) 00380-9$

[39] Saraydin D., Karadag B., Çetínkaya S., Güven O.: Preparation of acrylamide/maleic acid hydrogels and their biocompatibility with some biochemical parameters of human serum. Radiation Physics and Chemistry, 46, 1049-1052 (1995).

DOI: $10.1016 / 0969-806 X(95) 00318-\mathrm{R}$

[40] Singhal R., Gupta I.: A study on the effect of butyl methacrylate content on swelling and controlledrelease behavior of poly (acrylamide-co-butyl-methacrylate-co-acrylic acid) environment-responsive hydrogels. International Journal of Polymeric Materials, 59, 757-776 (2010).

DOI: $10.1080 / 00914037.2010 .483216$ 
[41] Li Q., Ma Z., Yue Q., Gao B., Li W., Xu X.: Synthesis, characterization and swelling behavior of superabsorbent wheat straw graft copolymers. Bioresource Technology, 118, 204-209 (2012).

DOI: $10.1016 /$ j.biortech.2012.03.028

[42] Pourjavadi A., Mahdavinia G. R., Zohuriaan-Mehr M. J.: Modified chitosan. II. H-chitoPAN, a novel pHresponsive superabsorbent hydrogel. Journal of Applied Polymer Science, 90, 3115-3121 (2003).

DOI: 10.1002/app.13054

[43] Mahdavinia G. R., Mousavi S. B., Karimi F., Marandi G. B., Garabaghi H., Shahabvand S.: Synthesis of porous poly(acrylamide) hydrogels using calcium carbonate and its application for slow release of potassium nitrat. Express Polymer Letters, 3, 279-285 (2009). DOI: $10.3144 /$ expresspolymlett.2009.35

[44] Kaith B. S., Sharma K., Kumar V., Kalia S., Swart H. C.: Fabrication and characterization of gum ghattipolymethacrylic acid based electrically conductive hydrogels. Synthetic Metals, 187, 61-67 (2014).

DOI: 10.1016/j.synthmet.2013.10.021

[45] Tiwari A., Gong S.: Electrochemical detection of a breast cancer susceptible gene using cDNA immobilized chitosan-co-polyaniline electrode. Talanta, 77, 1217-1222 (2009).

DOI: $10.1016 /$ j.talanta.2008.08.029

[46] Tiwari A., Kumar R., Prabaharan M., Pandey R. R., Kumari P., Chaturvedi A., Mishra A. K.: Nanofibrous polyaniline thin film prepared by plasma-induced polymerization technique for detection of $\mathrm{NO}_{2}$ gas. Polymers for Advanced Technologies, 21, 615-620 (2010). DOI: $10.1002 /$ pat. 1470

[47] Tiwari A., Shukla S. K.: Chitosan-g-polyaniline: A creatine amidinohydrolase immobilization matrix for creatine biosensor. Express Polymer Letters, 3, 553559 (2009).

DOI: 10.3144/expresspolymlett.2009.69
[48] Shumaila, Alam M., Siddiqui A. M., Husain M.: Synthesis, characterization and properties of Se nanowires intercalated polyaniline/Se nanocomposites. Express Polymer Letters, 7, 723-732 (2013).

DOI: 10.3144 /expresspolymlett.2013.70

[49] Patil R. C., Patil S. F., Mulla I. S., Vijayamohanan K.: Effect of protonation media on chemically and electrochemically synthesized polyaniline. Polymer International, 49, 189-196 (2000).

DOI: 10.1002/(SICI)1097-0126(200002)49:2<189:: AID-PI325>3.0.CO;2-9

[50] Jósefowicz M. E., Epstein A. J., Tang X.: Protonic acid doping of two classes of the emeraldine form of polyaniline. Synthetic Metals, 46, 337-340 (1992). DOI: 10.1016/0379-6779(92)90359-Q

[51] Kulkarni M. V., Viswanath A. K., Marimuthu R., Seth T.: Spectroscopic, transport, and morphological studies of polyaniline doped with inorganic acids. Polymer Engineering and Science, 44, 1676-1681 (2004). DOI: $10.1002 /$ pen.20167

[52] Tiwari A., Sen V., Dhakate S. R., Mishra A. P., Singh V.: Synthesis, characterization, and hoping transport properties of $\mathrm{HCl}$ doped conducting biopolymer-copolyaniline zwitterion hybrids. Polymers for Advanced Technologies, 19, 909-914 (2008).

DOI: $10.1002 /$ pat.1058

[53] Kroschwitz J. I.: Electrical and electronic properties of polymers: A state-of-the-art compendium. Wiley, New York (1988).

[54] Malik H., Gupta N., Sarkar A.: Anisotropic electrical conduction in gum Arabica - A biopolymer. Materials Science and Engineering: C, 20, 215-218 (2002). DOI: $10.1016 / \mathrm{S} 0928-4931(02) 00036-\mathrm{X}$

[55] Li Q., Cruz L., Phillips P.: Granular-rod model for electronic conduction in polyaniline. Physical Review B, 47, 1840-1845 (1993).

DOI: 10.1103/PhysRevB.47.1840 